\title{
Esteem, Social Norms and Status Inequality
}

\author{
Costanza Porro' ${ }^{(D)}$
}

Accepted: 7 September 2021 / Published online: 17 September 2021

(C) The Author(s) 2021

\begin{abstract}
When we appraise others as talented or virtuous, we esteem them: we register admiration of their traits and virtues. It is generally believed that, unless they involve a violation of respect, distributions of esteem are not a concern from the point of view of justice. In this paper, I want to dispute this commonly-held view. I will argue that attributions of esteem can become problematic when a particular trait becomes such a uniquely relevant source of social esteem in a community that its absence becomes a reason to regard others as less than full members of the community. For instance, in contemporary capitalist societies those perceived as lacking certain socially valued traits and unable or unwilling to make certain kinds of contribution to the community, such as those who are unemployed or have committed criminal offences, are widely disesteemed and also regarded as inferior qua members of the community by others. From the fact that they fail to possess particular qualities a broader negative judgment of their ability to contribute to the community is inferred. Moreover, their failure to gain esteem in these pervasive domains eclipses their possession of other esteem-worthy traits as well as other positive contributions they might have made to society. This perception of inferiority renders it impossible for them to live on equal terms with other citizens. I argue that as egalitarians we should oppose these distributions of esteem.
\end{abstract}

Keywords Respect $\cdot$ Esteem $\cdot$ Social equality $\cdot$ Egalitarian ethos $\cdot$ Social norms

\section{Introduction}

While there is a substantial agreement that inequalities of respect are objectionable because respect should be conferred to all equally, many believe that the distribution of esteem is not a concern from the point of view of justice. It is argued that unless inequalities of esteem involve disrespect, the distribution of esteem should be left to be determined by

Costanza Porro

costanza.porro@gmail.com

1 Institute for Philosophy, University of Hamburg, Hamburg, Germany 
the attitudes and actions of individual and collective agents in society. In this paper, I have two aims: firstly, I identify a set of inequalities of esteem widespread in current capitalist democracies which should be a concern from an egalitarian point of view. Secondly, I reject the commonly held view that inequalities of esteem should be regarded as unjust only because they involve respect violations. Tim Scanlon, Carina Fourie and Timo Jütten have recently argued along these lines, claiming that inequalities of esteem are also problematic when they make certain members of the community feel inferior (Fourie 2015; Jütten 2017; Scanlon 2000). I argue that this is not the whole story. Inequalities of esteem can also be objectionable because they undermine equal status. If we care about status equality, we should object to these distributions of esteem.

In what follows, after a presentation of the concepts of respect and esteem, I discuss the two main alternative positions in the literature. To illustrate my view, in Sect. 3 I present two cases, one of which is an objectionable inequality of esteem, while the other one describes a legitimate inequality of esteem. I go on to identify two features that make inequalities of esteem objectionable: the spill-over effect and the eclipsing effect. I argue that it is precisely in these two features that the difference between the two cases lays. In Sect. 4, I reply to a possible objection by arguing that we attribute social esteem to other members of the community according to the standards of contribution, i.e. a limited set of traits which refers to one's ability to contribute to socially shared goals. I then move to analyse the relationship between esteem and respect, in order to show that while the fact that inequalities of esteem can involve violations of respect is one reason to regard them as objectionable, there is a separate reason to object to them, which has to do with their impact on the status of some citizens. When widely accepted norms that regulate the distribution of esteem convey the judgment that some are not full members of the community, they cannot enjoy equal status. Finally, I discuss and reply to a possible objection centred on the idea that what is objectionable about these distributions of esteem is not their impact on status, but the fact that they are incorrect judgments of esteem.

\section{The Concepts of Respect and Esteem}

Let's start with a well-known distinction: the one between "recognition respect" and "appraisal respect" (Darwall 1977). Recognition respect, which I will call "respect" in this paper, is the disposition to give appropriate consideration in one's practical deliberations to some fact about the object of respect and to regulate one's conduct by constraints derived from that fact. In the case of persons, recognition respect is usually understood as recognition of the fact that one possesses the characteristics that make one a person and therefore there are certain ways in which one cannot be treated by others. Appraisal respect, or "esteem", on the other hand, is an attitude of positive appraisal of a person or their merits, which can be directed at various features, from musical talent to honesty, depending on the standards used to attribute esteem. When conferring esteem in a given domain, one evaluates another's performance in that domain. While esteem is a matter of degree and one can receive more or less esteem depending on the extent to which one is judged to possess an esteem-worthy trait, respect does not come in degrees. Respect is binary in the sense that either a given being is entitled to a particular form of respect, such as respect for persons, or she is not. 
A failure to respect others is a paradigmatic moral wrong. Conversely, esteem is usually understood as morally optional: no one is entitled to a certain degree of esteem, for at least two reasons. Firstly, unlike respect, the attribution of esteem is conditional on the possession of particular traits that are not possessed by all to and to the same degree. Secondly, at least in some cases, whether one considers certain traits esteem-worthy seems itself optional, therefore, one is not morally required to esteem another because if one does not value the trait in the first place. For these reasons, many believe that violations of respect are objectionable from the point of view of justice, while the distribution of esteem is only problematic if it involves failures of respect. This is the view that I set out to reject in this paper.

Before embarking in this discussion, more needs to be said about esteem and its mechanisms. Several factors determine how esteem is distributed. The group of those in a position to confer esteem is relevant to the distribution of esteem because it determines which traits or characteristics attract esteem (Brennan and Pettit 2005, Chap. 2). Moreover, while all domains of esteem, by definition, attract some esteem, there is a ranking between them and excellence in some domains attracts more esteem than excellence in others (Fourie 2015, 103).

In what follows, I do not claim that egalitarians should oppose the very fact that people attribute esteem to others nor do I argue against unequal distributions of esteem per se, or advance as an alternative an equal distribution of esteem. ${ }^{1}$ My objective in this paper is to identify ways in which esteem operates which are incompatible with the egalitarian ideal but distinct from violations of respect, namely cases in which esteem undermines equal status. To illustrate this, I will often use examples taken from the distribution of esteem in contemporary capitalist societies. This is one of the reasons to engage in this analysis as it shows that egalitarians have a reason to be concerned about the workings of social esteem in our societies.

At this point, one might wonder whether we should not also take into account the positive function that these norms of esteem might play, for instance in terms of the values and positive behaviours that they promote. If so, we should reflect on whether alternative non-objectionable norms of esteem could also fulfil this role. There are three considerations to be made in this connection. The first is that norms of esteem play a positive role only when esteem captures genuine contribution to the community which, as I discuss later, is not always the case for these distributions of esteem. The second is that intuitively is not that difficult to imagine a society where esteem is still accorded to socially valuable traits, thereby promoting these traits, but in ways that do not create inequalities of status. Thirdly, and most importantly, I want to contend that the objection articulated in this paper is of particular relevance and is likely to trump a number of other considerations in favour of these norms. In other words, the significance of equality of status and the fact that these norms of esteem, as I argue in the paper, undermine equal status is a conclusive reason to abandon such distributions of esteem even if that means foregoing some of the positive effects that they have.

\footnotetext{
${ }^{1}$ For an argument for near equality of esteem, see (Baker 2015).
} 


\section{Objectionable Inequalities of Esteem: Runciman, Scanlon, Fourie and Jütten}

William G. Runciman is one of the main advocates of the view that all inequalities of respect are illegitimate, while inequalities of esteem are not to be considered objectionable (Runciman 1967). The act of disesteeming is not problematic in itself, but only if disesteem is expressed in a way that involves a failure to respect others, that is to say, when the judgment of disesteem is accompanied by actions that are disparaging or humiliating. To give an example, there is a difference between expressing disesteem by booing an actor and by spitting on him. The latter expression of esteem invokes a convention that has a humiliating and disparaging meaning. The reason why Runciman focuses on the ways esteem and disesteem are conveyed is that he is interested in whether the norms of respect govern relationships between people. However, by focusing solely on respect, Runciman neglects another dimension of the distribution of esteem: its potentially detrimental effects.

Scanlon and Fourie defend the view that inequalities of esteem can be objectionable also in virtue of their consequences. They argue that people who are at the bottom of certain hierarchies of esteem often feel inferior to others and this undermines their self-respect. A similar view is articulated by Jütten who argues that a severe lack of social esteem is a threat to dignity because it undermines people's sense of self-worth.

Scanlon argues that these feelings become a matter of justice only when they are caused by institutions, while Fourie correctly, in my view, maintains that, while institutional support is likely to make them more pervasive, inequalities of esteem can be problematic even in the absence of institutional backing. Not only is it the case that certain inequalities of esteem are illegitimate even without the support of institutions but, furthermore, the critical potential of this analysis rests precisely in tackling norms of esteem independently from the role of institutions in creating as well as eradicating them.

Besides the possibility that certain inequalities of esteem generate feelings of inferiority, I argue that there is another reason to be worried about them. If a domain of esteem is particularly pervasive and considered the most important standard of assessment, social norms that convey that those who fail according to these standards are less than full members of the community are likely to be in place. In these cases, others will be inclined to look at one not merely as less deserving of esteem but as a less than a full member of the society and this would have an impact on their status.

By status, I refer to one's rank or position in the community as defined by political and social institutions and other members of society. By status as a (social) equal or status as a member of the community, I mean the kind of status and related respect that individuals are entitled to in virtue of their being moral persons and members of a political community. While status does come in degree and one can enjoy higher or lower status, egalitarians are committed to equality of status for all - the realisation of a society in which all are accorded the status of members of the community, of social equals. Whether one is able to stand as an equal depends on whether one is in the right kind of relationship with the state and fellow citizens, and has certain entitlements, such as basic rights and a certain amount of wealth and power, as a result of being in these relationships. ${ }^{2}$ The quality of the relation-

\footnotetext{
${ }^{2}$ Unlike other contemporary theories of equality social egalitarianism does not focus on the distribution of certain goods but maintains that equality primarily concerns the quality of social relationships. (Anderson 1999; Scanlon 2018; Scheffler 2003; Wolff 2015)
} 
ship with other citizens and their attitudes are deemed central by social egalitarians because one's ability to stand as an equal is taken to crucially depend on the way one is treated and regarded by others. Disparaging social norms and attitudes, relationships of domination, subordination and unequal power are central to the social egalitarian project because they undermine people's status and their self-respect. ${ }^{3}$ For the purpose of my argument, I do not need to settle the disagreement about what these egalitarian relationships should precisely look like. My aim is to argue that certain kinds of inequalities of esteem are problematic because some members of the community are regarded and treated as less than full members of the community by others and thereby do not enjoy equal status. Therefore, for my argument to be convincing, I only need two claims to be persuasive. Firstly, that one does not enjoy equal status when one is treated and regarded as less than a full member of the community by a critical number of fellow members, a claim that is widely accepted among egalitarians. Secondly, that the distribution of social esteem is governed by norms that convey that of those who fail to secure it are not equal members of the community, a claim that I will defend in the next two sections. If my arguments are convincing, those who believe that members of the political community should have equal status should be concerned about certain kinds of inequalities of esteem.

At this point, the question might arise of whether even if these distributions of esteem are indeed objectionable they should be left unregulated because they are beyond the purview of justice, they belong to the private sphere. In replying to this concern, it is important to point out that, as feminist philosophers have long argued, there are good reasons not to take the distinction between the public and the private sphere as given and instead re-draw its boundaries, in cases in which they serve the function to hide from the sight of justice problems which should be under its scope. Equal status concerns are central to the egalitarian ideal; therefore, even if the attribution of esteem might appear a private issue, it is indeed an issue of justice when it leads to inequality of status in virtue of the existence of particular social norms of esteem, on the background of which individual attributions of esteem take place. Citizens' duty to treat others as equals encompasses the duty not to uphold and reinforce institutions and norms that undermine equality of status.

\section{Which Inequalities? The Spill-Over and Eclipsing Effects}

I will now present two cases in which one is the addressee of disesteem, which allow me to illustrate which kinds of inequalities of esteem are objectionable and for which reasons. This analysis, which I conduct in the next two sections, paves the way to the discussion of the relationship between esteem and respect carried out in Sect. 5. The first case is the simple case of someone who lacks a trait which attracts esteem and, as a consequence, is not esteemed in that domain. This would, for instance, be the case of a philosophy lecturer who is disesteemed by her colleagues because she lacks the skills to be a good philosopher. I will

\footnotetext{
${ }^{3}$ A point of contention in the social egalitarian literature is whether egalitarians should be concerned about (a) how citizens act towards one another, (b) which attitudes they have towards one another, i.e. how they regard one another, or (c) which attitudes they express. (Voigt 2018) On this issue, I side with Anderson who argues that all three dimensions matter in the relationship between members of the political community (Anderson 1999; Anderson and Pildes 2000). In the case of esteem, often a judgment of esteem will involve the expression of disesteem and other behavioural upshots. However, a judgment of esteem can also be objectionable independently of whether it translates in actions and expression of these attitudes.
} 
refer to this as the case of bad performance. The second case, like the first one, is also one in which one receives negative esteem in a given domain because one lacks certain features. However, the domain of esteem in question is not only one among others, but it is one that is particularly pervasive in a given society. An example would be those who are unemployed in contemporary capitalist societies. I will refer to this as the case of failure in a pervasive domain. I contend that egalitarians should not be concerned with cases like the bad performance case ${ }^{4}$, but should instead regard failure in a pervasive domain cases as objectionable inequalities of esteem.

There are various features that make inequalities of esteem concerning from a social egalitarian point of view. These include the absence of genuine equality of opportunity to achieve esteem in cases in which members of certain disadvantaged social groups, such as women, do not have the same chances to compete and achieve esteem, especially in those domains which attract more social esteem, such as high-status professions. Moreover, the extent to which a society put emphasis on the competition for esteem can also be worrisome from a social egalitarian perspective ${ }^{5}$. Such factors are typically understood as problematic because the inequalities of esteem that exhibit these features are taken to violate respect and/ or make some members of society feel inferior. In this paper, I want to focus on a different issue, which is central to the distribution of social esteem in contemporary capitalist societies: some judgments of esteem based on one's contribution to socially shared goals become a broad assessment of a person qua members of the community. When one fails according to these standards, one's equal status as a member of the political community is called into question. Some of the factors mentioned earlier, like the emphasis on the competition for esteem in a society, can play a role in making particular inequalities of esteem problematic; however, in this paper, I wish to identify a core, yet overlooked, reason why they are problematic, namely that they undermine equality of status.

The inequalities of esteem of failure in a pervasive domain cases undermine the equal status of some members of society because they are characterised by two features, which I call the spill-over effect and the eclipsing effect. The spill-over effect refers to the fact that certain judgments of esteem are not only a way to give people a score on a definable attribute but instead become an assessment of broader aspects of a person. One's performance according to that standard is used as evidence of the possession of other traits. For instance, in contemporary capitalist societies, the distribution of esteem according to professional success frequently does not simply reflect whether one possesses particular qualities that happen to be valued in a particular economy and society. On the contrary, its social meaning is often mixed with an evaluation of various other abilities and traits. Those who are at the top of these hierarchies tend to be regarded as intelligent and useful members of society, while those at the bottom as unintelligent and lazy and, if they receive government support, often described as free-riders. Similarly, those who are convicted for a criminal offence are not only regarded as people who have committed a crime but are routinely considered irredeemably bad people who have no regard for the values of the community and the rights of others (Kelly 2018, Chap. 1).

\footnotetext{
${ }^{4}$ While these kinds of judgment are almost always clouded by prejudice and biases, the case discussed here is the ideal case where the attribution of esteem is governed only by the quality of the performance.

5 For an interesting discussion of the various factors which make inequalities of esteem potentially problematic for social egalitarians see (Anderson 2012; Fourie 2015).
} 
Relatedly, these assessments have an eclipsing effect, in that they eclipse other domains of esteem, which cease to attract attention and become irrelevant. These pervasive domains become the only relevant standards in the assessment of others and other positive qualities and types of contribution are disregarded. For instance, the fact that one is unemployed often becomes a conclusive reason to regard them as lacking in many positive qualities and largely unable or unwilling to contribute to society, regardless of the other contributions one might have made. Such a judgment and attitude are even more commonplace when it comes to those who have committed a criminal offence. ${ }^{6}$

Fourie points in the direction of these phenomena when she presents two of the factors that should influence egalitarians in the assessment of inequalities of esteem: that of the pervasiveness of inequalities of esteem and the issue of whether a given inequality is bounded. Certain inequalities of esteem become pervasive when only a limited set of traits is valued. In these cases, succeeding according to these standards is likely to have much more influence on the way others regard and treat one compared to cases where a wider set of characteristics attract esteem (Fourie 2015, 99-100). An inequality of esteem is bounded when it has marked limits, that is to say when the esteem associated with good performance remains confined to the bounds of the domain in question (Fourie 2015, 100-104). However, the inequalities of esteem under examination are unbounded and pervasive, and it is precisely in virtue of these two features that they have the eclipsing effect and the spill-over effect, which renders them objectionable. Because a small number of traits are valued disproportionately in society, and the esteem arising from these traits is not limited to those domains, an attribution of esteem becomes a judgment on the possession of wider traits of a person and eclipses her performance in other domains. Therefore, the unbounded and pervasive nature of some inequalities of esteem, as described by Fourie, is the reason behind the existence of the eclipsing and spill-over effect which make certain inequalities of esteem objectionable.

To go back to our two original examples, we can now clearly see the difference between the bad performance case and the failure in a pervasive domain case. The attribution of esteem in the bad performance case does not have the features that render a distribution of esteem objectionable. Using the example of the bad philosopher, it is clear that this attribution of esteem does not have the spill-over effect, because it is not a judgment on various aspects of one's personality or a broad set of traits, but simply an assessment of one's philosophical abilities. Secondly, it does not have an eclipsing effect on other domains of esteem, because the ability to be a good philosopher is appreciated by some, but it is far from being the only focus of others' attention and uniquely relevant to one's standing in society. While this kind of distribution of esteem is unproblematic from the point of view of equality, those described in failure in a pervasive domain cases should be regarded as objectionable.

\footnotetext{
${ }^{6}$ The example of criminal offenders might strike some as problematic insofar as they believe that people should be disesteemed when they commit criminal offences. As I mentioned earlier, my aim is not to argue against unequal distribution of social disesteem per se but rather against distributions of social esteem which undermine equal status. Therefore, while it might be legitimate to disesteem those who commit criminal offences, it is objectionable to do so in a way that undermines their status. Moreover, while the way disesteem is attributed to criminal offenders is concerning in other respects, such as the fact that existing criminal justice systems often punish people for actions that are not legitimate grounds of social disesteemed, my core concern in this paper is how esteem undermines equal status.
} 


\section{Pervasive Domains of Esteem and The Standards of Contribution}

One might object to this picture that we do not attribute esteem to others only according to one standard, or a very limited set of standards. In our ordinary interaction, we assign esteem for a wide-ranging set of traits and abilities, which varies depending on the relationship with the person who is the addressee of esteem and the traits that we find esteem-worthy. In a friend, we might value the fact that she is a good listener, while in a colleague their ability to solve problems at stressful times. Moreover, some consider athletic abilities an important metric of esteem, while others hold musical talent in high regard. From this perspective, it might be hard to see how some domains of esteem could cease to be only one standard among many and become uniquely crucial for someone's status. In other words, one might wonder if any distribution of esteem can truly have a spill-over and eclipsing effect, which, as I argued earlier, make certain inequalities of esteem objectionable.

This might be true in our interpersonal relationships, where our standards of distribution of esteem tend to be numerous and variable. However, when we relate to others simply as members of the community we are unlikely to pay attention to how they score according to the various metrics discussed above, such as having musical talent, but instead, we concentrate on a smaller set of traits. The kind of traits we are likely to focus on when relating to other members of the community are those which are public, in the sense that information concerning one's performance in a domain is easy to access, and relevant in the context of the relationship between strangers who are members of the same community. Social esteem is typically distributed according to the degree to which one is perceived to be contributing to the realisation of socially and culturally defined values (Honneth 1996, 122-24). ${ }^{7}$

The historical development from pre-modern feudal societies to modern capitalist society has caused the breaking of the alloy of legal respect and social esteem (Jütten 2017, 262). While within a feudal order, respect and esteem were conferred in relation to one's social rank, in modern and contemporary capitalist societies respect is legally accorded to all to an equal degree, at least formally, and the competition for social esteem is open. Its attribution is determined by people's achievements and traits, which are evaluated in reference to whether they realise socially shared values. In the case of contemporary capitalist societies, we can identify two main ways to realise these values. Firstly, social esteem is accorded to those who fulfil the responsibility associated with their role as members of the community. One is required to do one's part to sustain the political community, typically through respecting its laws and contributing to the state via taxes and possibly other forms of contribution. This is why the failure to respect the rules of the polity is regarded by many as one of the main reasons to confer disesteem to members of the community. Secondly, one's professional occupation and success have substituted the traditional ordering of hierarchical feudal societies in the distribution of social esteem. Professional success and wealth are valued because they are considered evidence of the possession of praise-worthy qualities, such as intelligence and resourcefulness, but also because by contributing to economy one is perceived as making a positive contribution to society. This is the case because our societies are capitalist ones, characterised by an ethos that values these qualities and considers economic growth to be one of the primary goals of the community (Jütten 2017).

\footnotetext{
${ }^{7}$ It is important to note that while the distribution of esteem in personal relationships is more varied and mixed, the standards of social esteem also permeate intimate relationships.
} 
Henceforth, I will call these standards for the realisation of socially shared goals and values the standards of contribution.

What I said so far is not meant to suggest that the norms of social esteem operate in the same way in all contemporary capitalist societies. These societies differ in significant respects and both the extent to which the standards of contribution are all-encompassing, their exact content and the way they unfold depend on a variety of factors, including features that are specific to particular societies. The standards of contribution are shaped by social norms based on gender, race, class and other relevant social categories; moreover, what counts as a genuine contribution and the extent to which these norms are pervasive depend on public morality and norms of specific societies. However, the pattern I have described can be identified in many contemporary capitalist societies. My argument in this paper amounts to claim that insofar as it occurs, inequalities of esteem are objectionable.

In closing, it is interesting to note that in non-capitalist societies, in which esteem is also not conferred in relation to one's social rank, but the prevailing public morality is shaped around different values, the content of the standards of contribution can be very different. As Jiwei Ci notes, in Mao's China, being wealthy brought suspicion and stigma because it was seen in contradiction with the ethos of the community and socialist values. (Ci 2013, 128-32). While the content of these standards can be different in different social contexts, the mechanism is similar insofar as social esteem is only accorded to those who are regarded as contributors to the realisation of socially shared values.

\subsection{Objections to The Standards of Contribution}

Having described the standards of contribution, I will now discuss why they are objectionable. Three main objections can be formulated to the standards of contribution. The first objection is peripheral to my main argument and is based on the idea that these standards do not capture the actual contribution to society that members make in formal employment and other domains. For instance, the contribution of women is often underestimated because care roles and the activities typically performed by women attract less esteem, and compensation, than they should, given their core contribution to the functioning of our societies. Conversely, wealth, including inherited wealth, is often considered worthy of esteem while not necessarily positively contributing to the community.

The second and third critique refer to the eclipsing effect and the spill-over effect. Starting with the former, the issue is that one aspect of the life of certain people, such as those who are welfare-dependent or have committed a criminal offence, is seen as conclusive evidence of their inability to contribute to society. While they might have made, or have the capacity to make, a positive contribution to society in other ways, as parents, care-takers or members of the local community, their past and present positive contribution is eclipsed and they are disqualified from further competing for social esteem due to this failure. This is worrisome for two reasons: first, one might worry that people do not receive the amount of esteem to which they are entitled. While significant, this concern is not the central one in my paper, as I explain in Sect. 6. Secondly, in these cases, one is regarded as unable to contribute to the realisation of the values of the community in light of a particular aspect of their life. This is problematic if combined with the effects of the spill-over effect, which is the object of the third critique to the standards of contribution. 
According to the third critique, the spill-over effect is problematic insofar as this failure to contribute to societal goals is often seen as a reason to regard one as less than a full member of the community. The perceived inability to realise these values is regarded as a sign of a lack of those qualities that are a precondition for being an equal member of the political community. In a society where almost everyone places great value and importance on certain forms of accomplishment, which only some can attain, those who fail to do so will be considered inferior qua members of the community (Fraser and Honneth 2003, 28-30). So, in contemporary capitalist societies, those who have low-paying and insecure jobs, those who are unemployed and depend on the state for their livelihood or have broken the law are often seen as unable to meet the responsibility associated with citizenship and thereby less than equal members of the community. By making full membership conditional on one's ability to contribute to the community and fulfilling one's responsibility as a citizen, one calls into question the equal status of those who are perceived as lacking socially valued traits and unable to contribute. Those who fail according to the standards of contribution are thus unable to enjoy equal status. If we are egalitarians, we should reject the idea that anyone can be deprived of their status as an equal, regardless of their abilities, choices or actions. ${ }^{8}$

Interestingly, the ways in which the standards of contribution operate seem to bring into question the feasibility of the recommendation that virtually all egalitarians make when discussing inequalities of esteem, namely the need to multiply the arenas of competition for esteem to ensure that the highest number of people possible can compete and achieve some esteem (Anderson 2012; Baker 2015; Fourie 2015; Runciman 1967; Scanlon 2000; Walzer 1984). The multiplication and diversification of the standards of esteem is a normatively appealing solution because it would eliminate pervasive domains of esteem; therefore, if feasible, it could be an appropriate response to the problems discussed in this paper. However, the tendency of social esteem to focus on a particular set of traits which are public and relevant to others qua members of the political community described so far casts doubt on its feasibility insofar as it appears to be a tendency of different kinds of societies. What I have said in this paper does not exclude the possibility that there could be a society where the distribution of social esteem is organised around a plurality of standards, which is an empirical question that I cannot address here. Nonetheless, at the very least it suggests that a significant shift from the ethos of various societies, including of contemporary capitalist societies, might be necessary for realising it. ${ }^{9}$

\section{Two Types of Wrongs: Disrespect and Status Diminution}

As we have seen earlier, inequalities of esteem are typically considered objectionable for two reasons, because they amount to violations of respect and because they make people

\footnotetext{
${ }^{8}$ It is interesting to note that there are likely to be cases where positive esteem, rather than disesteemed, is attributed to people in ways that are structurally similar to the ones discussed in this paper. While the cases discussed in this paper are more urgent for egalitarians, such cases are also problematic because they accord a superior status to some members of the community.

${ }^{9}$ Discussing the merits of a genuinely meritocratic society, Scanlon argues that while in such a society the competition for esteem would be fairer, the feelings of inferiority experienced by those who do not succeed would be heightened. (Scanlon 2000,54). A similar argument can be made for the inequalities of status discussed in this paper.
} 
feel inferior. My core concern in this paper is instead with their impact on the status of members of the community. In this section, I aim to show that we should distinguish between two different wrongs when we discuss objectionable distributions of esteem: the wrong of disrespect and the wrong of status diminution.

Firstly, the attributions of esteem discussed in this paper cannot be reduced to individual violations of respect because of their collective and systemic nature. Not all instances of violations of respect are cases in which someone's status is undermined. Individuals' attitudes and single instances of respect are not a component of one's status; thus, inequalities of esteem do not undermine one's status because of single violations of respect. Rather, the way others see one is relevant to one's status only when they take the form of societal attitudes and social norms. The problem arises when the actions and attitudes of individuals happen against a backdrop of objectionable social norms, and it is the existence of these norms, how widespread they are, and the extent to which they permeate relationships and the working of institutions that undermine people's equal status. To illustrate this point further, one can quite easily think of cases where one is disrespected by another member of their community but their status is not undermined. Imagine someone with red hair who is treated as an inferior on the grounds of his being a redhead. While we would say that he is a victim of disrespect, in the absence of a social norm which disparages one aspect of his identity and a critical mass of people subscribing to that norm, we would not say that this person's status has been undermined. Therefore, as individual violations of respect do not undermine equal status, the inequalities of esteem discussed in my paper and individual violations of respect cannot be wrong for the same reasons, they cannot share the same wrong-making features.

If individual failures to respect others are not a good candidate to explain the wrongness of inequalities of esteem, one might still wonder whether inequalities of respect might be a better candidate. Respect does not necessarily operate in an idiosyncratic way and often individual instances of disrespect are parts of wider inequalities of respect, which rank some members of the community as superior and others as inferior. With inequalities of respect we seem to be getting closer to the concern articulated in this paper; however, two considerations are to be made about the difference between failures of respect and the objectionable inequalities of esteem discussed in this paper.

Firstly, in the cases discussed in this paper, because of the eclipsing and spill-over effect discussed earlier, attributions of esteem in one domain eclipse other domains of esteem and become a broader judgment of a person - the judgment that that person is unable or unwilling to contribute to the community. The perceived inability to contribute to society's values, in turn, becomes a reason to regard others as less than full members of the political community because membership is regarded as conditional on the fulfilment of specific responsibilities. However, this does not necessarily lead to disrespecting others by denying their status as equal moral persons worthy of basic moral respect. In some cases, those who fail according to the standards of contribution are also disrespected insofar as they regarded and treated as less than equal moral persons. To give an example, in the UK, those who live in council estates and are welfare-dependent are sometimes described using dehumanising language or as lacking intellectual capacities and self-control, which can be interpreted as a way to suggest that they lack, or have in minor degrees, those rational capacities deemedby many to make one a moral equal. ${ }^{10}$ However, while in real-life circumstances there will be

${ }^{10}$ Owen Jones, Chavs: The Demonization of the Working Class, [New] edition (London: Verso, 2016). 
some grey areas, the violation of respect based on the idea that certain members of the community lack moral personhood is not essential to the attributions of esteem described in this paper. Considering others as unable to contribute to the societal goal is objectionable when it leads to a failure to regard them as equal participants to the civic enterprise thereby undermining their equal status. However, both the content of the attitude and its justifications are different as what is at stake in the inequalities of esteem discussed in this paper is not a lack of moral respect due to other human beings in virtue of their being equal moral persons.

The second consideration aims at distinguishing between two kinds of wrongs: a relational wrong of disrespectful regard and treatment and a positional wrong of status diminution. When we think about status inequality, we do not primarily think about the way people treat each other, but instead, we focus on whether individuals have equal status, whether they have the rights and the means to stand as equals. This includes, as discussed in Sect. 2, being the addressees of the right kind of regard, attitudes and treatment from fellow citizens as well as having basic rights and a degree of wealth and income that allows one to live on equal terms with others. Therefore, one's status would be undermined also if one did not have appropriate resources or basic rights. Focusing on whether people enjoy equal status, we can understand systematic violations of respect, unlike individual ones, as problematic because, while in both cases there is disrespectful regard and treatment, only in cases of systematic disrespect one lacks the relevant societal attitudes to be able to stand as an equal. Thus, we can identify two types of wrong. The wrong of status diminution is positional, rather than relational, and does not lay in the fact that some fail to show the appropriate regard or treatment towards one. Rather, the issue is that B occupies an inferior position and does not have the means to stand as an equal in front of others, be it wealth or, as in this case, the appropriate regard of other members of the community. In this case, this is the result of $\mathrm{B}$ being regarded and treated in certain ways by her fellow citizens, however, the core issue is B's resulting lack of equal status. B is deprived of what she is entitled to in virtue of her being a member of the political community. Conversely, the wrong of disrespectful regard and treatment is a relational wrong that has to do with the way an agent regards or behaves towards another and their failure to regard and treat them in accordance with their status. In conclusion, inequalities of esteem can be objectionable because they undermine the equal status of some members of the community, and this concern is distinct from that arising from disrespectful regard and treatment.

\section{A Final Objection: Egalitarian Concern or The Inaccurate Attribution of Esteem?}

In the last part of the paper, I consider a final objection to my proposal. One could argue that the issue with the distributions of esteem that I have been considering can all be traced back to the fact that the attributions of esteem in question are inaccurate. According to this objection, the objectionable inequalities of esteem I have been discussing so far is a subset of a wider range of cases of inaccurate attribution of esteem and the reasons why they should be criticised, like other cases of mistaken attribution of esteem, is that they do not confer to people the amount of esteem that they deserve.

A difficulty in replying to this objection is that the cases I have described in this paper are mistaken attributions of esteem. In virtue of the pervasiveness of some domains, those who 
perform poorly according to the standards of contribution are not simply judged as lacking the specific skills that would allow them to succeed in those domains, but they are also regarded as lazy, unintelligent, and unable and unwilling to contribute to society. The latter ascriptions of esteem are mistaken because these judgements cannot be derived from one's failure in these domains, e.g. one's lack of success in the job market.

Nonetheless, while this objection captures the phenomena that I am describing, it does not point to the right reasons to object to these inequalities of esteem. Borrowing an expression from metaethics, we can call this an instance of the wrong kind of reasons problem. ${ }^{11}$ In metaethics, this describes a case where something counts as a reason in favour of something else, but it is not the right type of reason for it. For instance, if someone threatens to kill you unless you believe $\mathrm{p}$, this counts as a reason for believing $\mathrm{p}$, as it is in some way good for you to believe $p$, even though it has no bearing on the question of whether $p$ is true or false. Similarly, this objection points to a reason why these inequalities of esteem are objectionable but misses the most crucial aspect of this set of cases. What the cases I have been discussing have in common and what makes them worthy of the attention from the point of view of egalitarian justice is the correlation between a certain distribution of esteem and the existence of disparaged social identities. There are two key features that the objectionable inequalities of esteem discussed in this paper do not share with other incorrect distributions of esteem. Firstly, the way in which esteem and social norms operate in these cases make these attributions of esteem a description of a wide set of traits of a person, rather than of their performance in a bounded domain. Secondly, in virtue of their being an assessment of a broad range of features and having an eclipsing effect on other domains of esteem, these distributions of esteem convey that some are less than full members of the community.

The comparison between two cases of mistaken attribution of esteem, one that involves social norms that express the lesser membership of those who perform poorly in that domain and one that does not make this contrast even more apparent. Let us consider a revised version of the bad philosopher case. In this scenario, which I call the misunderstood philosopher case, the person in question is a good philosopher but she is mistakenly disesteemed by other philosophers. Let us assume this is not the result of other aspects of her social identity, but simply of the inability of those in her circle to correctly assess her abilities. Even if this negative judgment of esteem has a very negative impact on her self-esteem, the only complaint that she can express is that she has been judged unfairly and attributed the wrong amount of esteem given her performance. While she would be treated differently from those who are regarded as good philosophers, the kind of treatment she receives, such as not being invited to conferences, is limited to the academic community. She will be regarded and treated as a bad philosopher by other philosophers, but not as a less than a full member of the political community by others because it is only her philosophical abilities that are under evaluation in this domain. In the other case, by contrast, while one aspect of the complaint would be that the esteem received does not reflect one's abilities and performance, another element of the complaint would be that one is treated as an inferior by others and does not enjoy equal status as a consequence of this ascription of esteem.

${ }^{11}$ For a presentation of the wrong kind of reasons problem see (Crisp 2000). 


\section{Conclusions}

In this paper, like Scanlon, Fourie and Jütten, I have rejected the view that inequalities of esteem should be considered objectionable only when they involve violations of respect but, unlike them, I have denied that this is only because of the feelings of inferiority such inequalities generate. I have argued that we should also focus on the impact on the equal status of those who fail according to these standards of esteem. I have argued that the distribution of social esteem in contemporary capitalist societies is regulated by norms which undermine equal status by pointing to two aspects of existing inequalities of esteem that render them objectionable: the spill-over effect and the eclipsing effect.

Funding Open Access funding enabled and organized by Projekt DEAL.

Open Access This article is licensed under a Creative Commons Attribution 4.0 International License, which permits use, sharing, adaptation, distribution and reproduction in any medium or format, as long as you give appropriate credit to the original author(s) and the source, provide a link to the Creative Commons licence, and indicate if changes were made. The images or other third party material in this article are included in the article's Creative Commons licence, unless indicated otherwise in a credit line to the material. If material is not included in the article's Creative Commons licence and your intended use is not permitted by statutory regulation or exceeds the permitted use, you will need to obtain permission directly from the copyright holder. To view a copy of this licence, visit http://creativecommons.org/licenses/by/4.0/.

\section{References}

Anderson ES (1999) What Is the Point of Equality? Ethics 109(2):287-337. https://doi.org/10.1086/233897 Anderson ES (2012) Equality. In: Estlund D (ed) The Oxford Handbook of Political Philosophy. Oxford University Press,Oxford, pp 40-57

Anderson ES, Pildes RH (2000) Expressive Theories of Law: A General Restatement. U Pennsylvania Law Rev 148(5):1503-1575. https://doi.org/10.2307/3312748

Baker J (2015) Conceptions and Dimensions of Social Equality. In: Fourie C, Schuppert F, and WallimannHelmer I (eds) Social Equality: On What It Means to Be Equals. Oxford University Press, Oxford; New York, pp 65-87. https://doi.org/10.1093/acprof:oso/9780199331109.001.0001

Brennan G, Philip Pettit (2005) The Economy of Esteem: An Essay on Civil and Political Society. Oxford University Press, Oxford; New York

Ci J (2013) Agency and Other Stakes of Poverty. J Poli Philos 21(2):125-150. https://doi. org/10.1111/j.1467-9760.2012.00417.x

Crisp R (2000) Value ? And What Follows. Philosophy 75(3):452-462. https://doi.org/10.1017/ S0031819100230519

Darwall SL (1977) Two Kinds of Respect. Ethics 88(1):36-49. https://doi.org/10.1086/292054

Fourie C (2015) To Praise and to Scorn: The Problem of Inequalities of Esteem for Social Egalitarianism. In: Fourie C, Schuppert F, and Wallimann-Helmer I (eds) Social Equality: On What It Means to Be Equals. Oxford University Press, Oxford; New York, pp 87-107

Fraser N, and Axel Honneth (2003) Redistribution or Recognition? A Political-Philosophical Exchange. Verso, London; New York

Honneth A (1996) The Struggle for Recognition: The Moral Grammar of Social Conflicts. MIT Press, Cambridge

Jütten T (2017) Dignity, Esteem, and Social Contribution: A Recognition-Theoretical View: Dignity, Esteem \& Social Contribution. J Poli Philos 25(3):259-280. https://doi.org/10.1111/jopp.12115

Kelly E (2018) The Limits of Blame: Rethinking Punishment and Responsibility. Harvard University Press, Cambridge

Runciman WG (1967) “Social” Equality. The Philos Q 17(68):221-230. https://doi.org/10.2307/2218156

Scanlon T (2000) The Diversity of Objections to Inequality. In: Clayton M and Williams A (eds) The Ideal of Equality. Palgrave Macmillan, Basingstoke, pp 41-59

Scanlon TM (2018) Why Does Inequality Matter? Oxford University Press, New York 
Scheffler S (2003) What Is Egalitarianism?. Philos Pub Aff 31(1):5-39. https://doi. org/10.1111/j.1088-4963.2003.00005.x

Voigt K (2018) Relational Equality and the Expressive Dimension of State Action. Soc Theory Pract 44(3):437-467. https://doi.org/10.5840/soctheorpract201853038

Walzer M (1984) Spheres of Justice: A Defense of Pluralism and Equality. Basic Books, New York

Wolff J (2015) Social Equality and Social Inequality. In: Fourie C, Schuppert F, and Wallimann-Helmer I (eds) Social Equality: On What It Means to Be Equals. Oxford University Press, Oxford; New York, pp 209-229

Publisher's Note Springer Nature remains neutral with regard to jurisdictional claims in published maps and institutional affiliations. 